Article

\title{
A Selective, Dual Emission $\beta$-Alanine Aminopeptidase Activated Fluorescent Probe for the Detection of Pseudomonas aeruginosa, Burkholderia cepacia, and Serratia marcescens
}

\author{
Linda Váradi ${ }^{1}{ }^{1 *}$, Elias Y. Najib ${ }^{1}$, David E. Hibbs ${ }^{1}$, John D. Perry ${ }^{2}$ and Paul W. Groundwater ${ }^{1}$ (I) \\ 1 The University of Sydney School of Pharmacy, Camperdown Campus, Sydney, NSW 2006, Australia; \\ elias.najib@sydney.edu.au (E.Y.N.); david.hibbs@sydney.edu.au (D.E.H.); \\ paul.groundwater@sydney.edu.au (P.W.G.) \\ 2 Microbiology Department, Freeman Hospital, High Heaton, Newcastle upon Tyne NE7 7DN, UK; \\ John.Perry@nuth.nhs.uk \\ * Correspondence: linda.varadi@rmit.edu.au
}

Academic Editor: Haiying Liu

Received: 10 September 2019; Accepted: 26 September 2019; Published: 30 September 2019

\begin{abstract}
Selective detection of $\beta$-alanyl aminopeptidase (BAP)-producing Pseudomonas aeruginosa, Serratia marcescens, and Burkholderia cepacia was achieved by employing the blue-to-yellow fluorescent transition of a BAP-specific enzyme substrate, 3-hydroxy-2-(p-dimethylaminophenyl)flavone derivative, incorporating a self-immolative linker to $\beta$-alanine. Upon cellular uptake and accumulation of the substrate by viable bacterial colonies, blue fluorescence was generated, while hydrolysis of the $\mathrm{N}$-terminal peptide bond by BAP resulted in the elimination of the self-immolative linker and the restoration of the original fluorescence of the flavone derivative.
\end{abstract}

Keywords: fluorescent probe; Pseudomonas aeruginosa; bacterial detection; self-immolative; 3-hydroxyflavone

\section{Introduction}

Early and specific detection of pathogenic bacteria is essential for informed clinical decision making and the selection of the appropriate therapeutic choices [1,2]. Colourimetric/fluorogenic enzyme substrates are acknowledged as gold standards and are often applied in clinical settings $[3,4]$. They incorporate a small coloured/fluorescent heterocyclic molecule covalently attached to an amino acid or sugar moiety that can be selectively metabolized by the bacterium of interest [5]. By tailoring the metabolic target (e.g., a sugar or amino acid) moiety within the substrate, selectivity and specificity can be achieved. $\beta$-Alanyl aminopeptidase (BAP) is specifically expressed by Pseudumonas aeruginosa, Burkholderia cepacia, and Serrratia marcescens, and can be targeted by $\beta$-alanyl moieties as the $N$-terminal fragments of peptide-like derivatives. P. aeruginosa is a multidrug resistant respiratory pathogen posing significant risk for immunocompromised patients [6], B. cepacia can cause severe lung infections in cystic fibrosis patients [7], while $S$. marcescens is a notorious causative agent of outbreaks in neonatal intensive care units (NICUs) [8].

Strain-specific aminopeptidase activity can be targeted by incorporating $N$-terminal amino acids as enzyme recognition moieties. For example, use of the colourimetric BAP substrates, 7-amino-1-pentyl-3H-phenoxazin-3-one 1 (1-pentylresorufamine [PRF]) (Scheme 1) [9], can result in up to $99.9 \%$ sensitivity; however, the time taken to obtain reliable results can be $18-72 \mathrm{~h}$. Fluorogenic enzyme substrates possess inherently enhanced detection sensitivity (as a result of displaying emitted 
light against a non-emitting background [10]) when compared to chromogenic alternatives, which can result in reduced diagnostic timeframes. Conjugation of $N$-terminal enzyme recognition moieties to hydroxylic chromophores/fluorophores can be achieved by incorporating a self-immolative linker between the chromophore and the amino acid [11]. For example, a BAP substrate incorporating a coumarin derivative 2 (Scheme 1) in liquid growth media enabled a diagnostic result within $6 \mathrm{~h}$ [12]. A large proportion of the previously published fluorogenic enzyme substrates detect metabolic activity based on an off-to-on fluorescent signal in the blue wavelength region [12,13], however some bacterial species display autofluorescence [14], potentially interfering with the detection signal. Thus, substrates that release fluorophores emitting at higher wavelengths, such as styrylcoumarin 3 [15], or those that display a significant wavelength shift before and after hydrolysis, for example 2-aminoacridone 4 [16], have potential in bacterial detection media (Scheme 1).
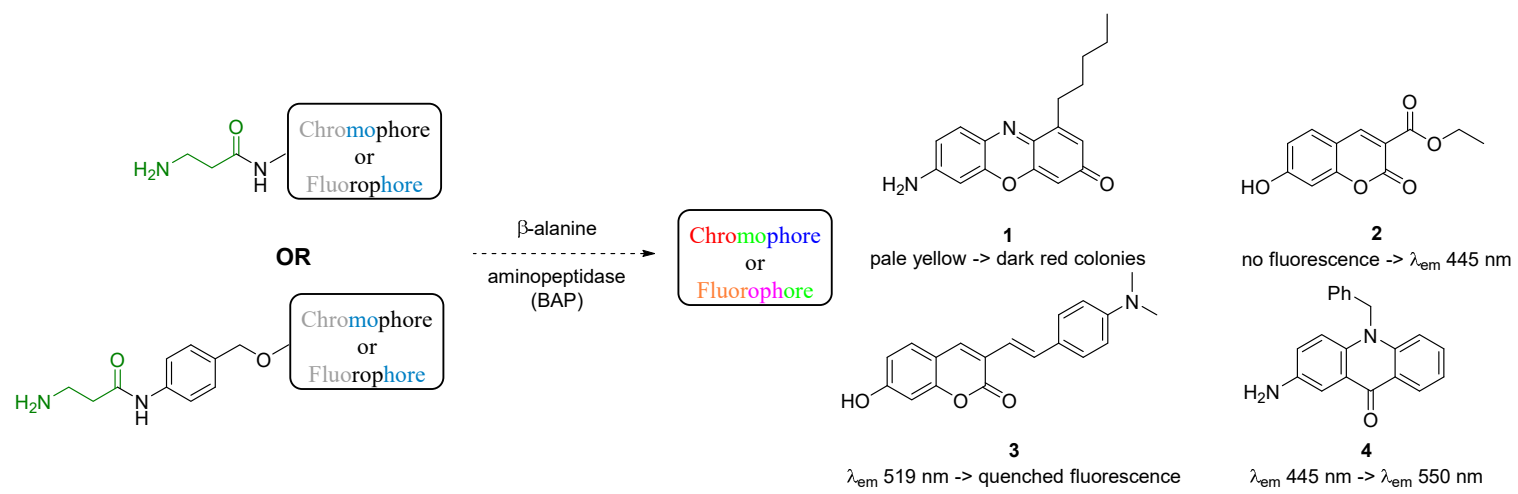

Scheme 1. Schematic representation of some amino and hydroxyl derivative chromogenic/fluorogenic probes used as $\beta$-alanyl aminopeptidase (BAP) substrates.

We based this work on the previously described chromogenic 3-hydroxyflavone (3HF) derivative 5, which was successfully employed for the detection of $\beta$-glucosidase activity in Gram negative bacteria. Upon incorporation into a suitable culture medium and subsequent enzymatic hydrolysis by bacteria, dark brown colonies were obtained due to the chelation of the released 3HF 6 with the metal ions $\left(\mathrm{Fe}^{3+}\right)$ present in the growth medium as a supplement (Figure 1a) [17]. Derivatives of 3HF are also known for their dual fluorescence, exhibiting emission via the excited states of both the normal 6N (at $440 \mathrm{~nm}$ ) and tautomer 6T (at $524 \mathrm{~nm}$ ) forms due to excited state proton transfer (ESIPT) (Figure 1b) [18]. The wavelength and the quantum yield of the ESIPT-derived emission peak is defined by (i) the ring substituents, and (ii) the molecular environment (e.g., solvent) of $3 \mathrm{HF}$ and its derivatives. Both factors contribute to the acidity of the flavone hydroxyl and/or the dipole moment of the molecule.

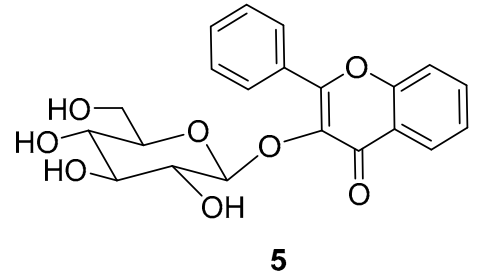

(a)
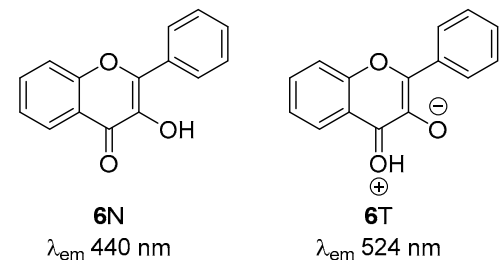

(b)

Figure 1. Chromogenic and fluorescence properties of 3HF 6, (a) Chromogenic substrate 5 and the produced dark brown colonies upon incubation and hydrolysis by Enterococcus faecium NCTC 7171 showing $\beta$-glucosidase activity. (b) 3-hydroxyflavone $6 \mathrm{~N}$ and its tautomer form $6 \mathrm{~T}$, the species responsible for dual fluorescence. 
When the possibility for excited state intramolecular proton transfer (ESIPT) is perturbed, the tautomer is less likely to form, thus the longer wavelength emission from this form is supressed. The introduction of electron donating groups (EDG) at the para-position of the 2-phenyl substituent of 3HF-for example as in $4^{\prime}$-dimethylamino-3HF 7 (Scheme 2a) - results in an increased dipole moment, prompting intramolecular charge transfer (ICT) that can potentially lead to the red shift of the emission maximum and the increase of the quantum yield in polar solvents when compared to unsubstituted 3HF 6 [19,20]. In polar aprotic solvents, 3-hydroxyflavones substituted with EDGs, such as 7 , have been reported to lack the dual $\mathrm{N}^{*}$ and $\mathrm{T}^{*}$ emission profile and to exhibit a single emission that arises from the hydrated normal form $\left(\mathrm{H}-7 \mathrm{~N}^{*}\right)$ with a maximum red-shifted from that of the $\mathrm{N}^{*}$ state $\left(\mathrm{H}-7 \mathrm{~N}^{*}\right.$ at $\sim 530-550 \mathrm{~nm}$ ) (Scheme 2a) [21,22]. The use of probes with this optical property within complex samples offers the added benefit of a detection signal that is outwith the autofluorescence region of any microorganisms that may be present. For example, the non-fluorescent probe $4^{\prime}$-diethylamino-3-(2",4"dinitrophenyl)oxyflavone 8 (Scheme $2 \mathrm{~b}$ ) was employed for thiolate sensing in aqueous media; upon thiolate-specific cleavage of the dinitrobenzyl moiety, the fluorophore emission at $538 \mathrm{~nm}$ was regenerated $\left(\lambda_{\mathrm{ex}}=417 \mathrm{~nm}\right)$ [23].

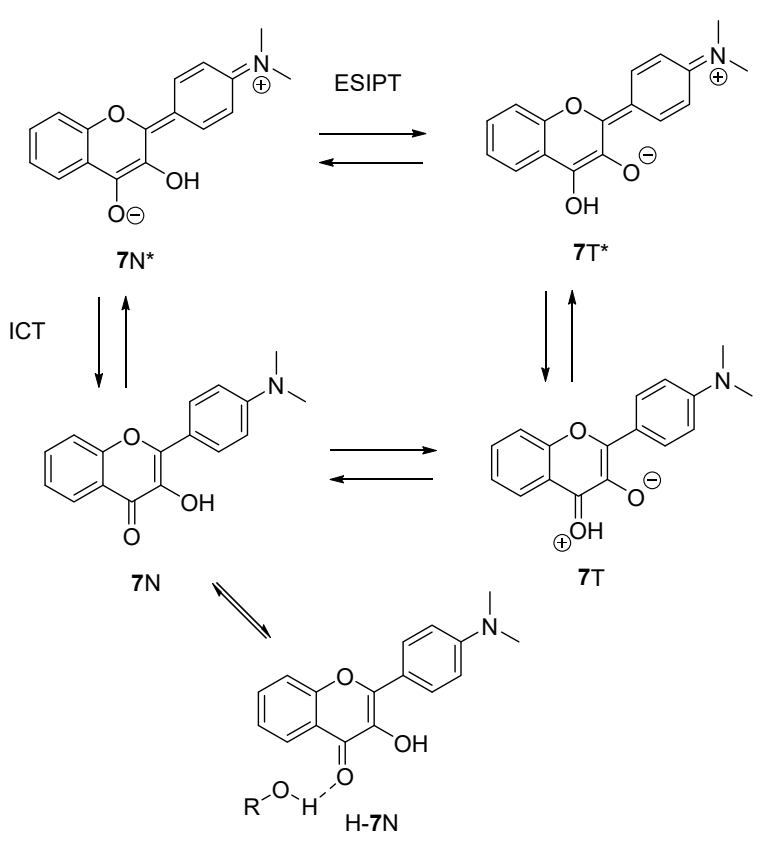

(a)

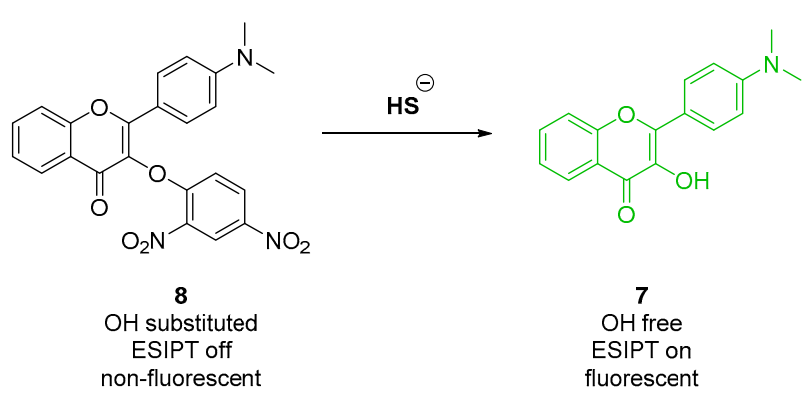

(b)

Scheme 2. Fluorescence properties of 3HF derivative 7. (a) The ground and excited state forms of tautomers and hydrated form of 7 , resulting in the fluorescence exhibited under various conditions. (b) dinitrobenzyl substituted 4'-diethylamino-3HF 8, a thiolate cleavable probe for the fluorescent sensing of thiolate in aqueous media. ESIPT: excited state intramolecular proton transfer. 
In this work, $4^{\prime}$-dimethylamino-3HF 7 was conjugated to $\beta$-alanine via a self-immolative $p$-aminobenzyloxy linker to obtain BAP substrate 9 (Scheme 3). The substrate was incorporated into agar, which was then inoculated with 20 clinically relevant microorganisms, including the BAP producers $P$. aeruginosa, B. cepacia, and S. marcescens. Visual observation and image analysis of the colonies were then conducted in order to evaluate the performance of the substrate in the detection and identification of BAP producers.

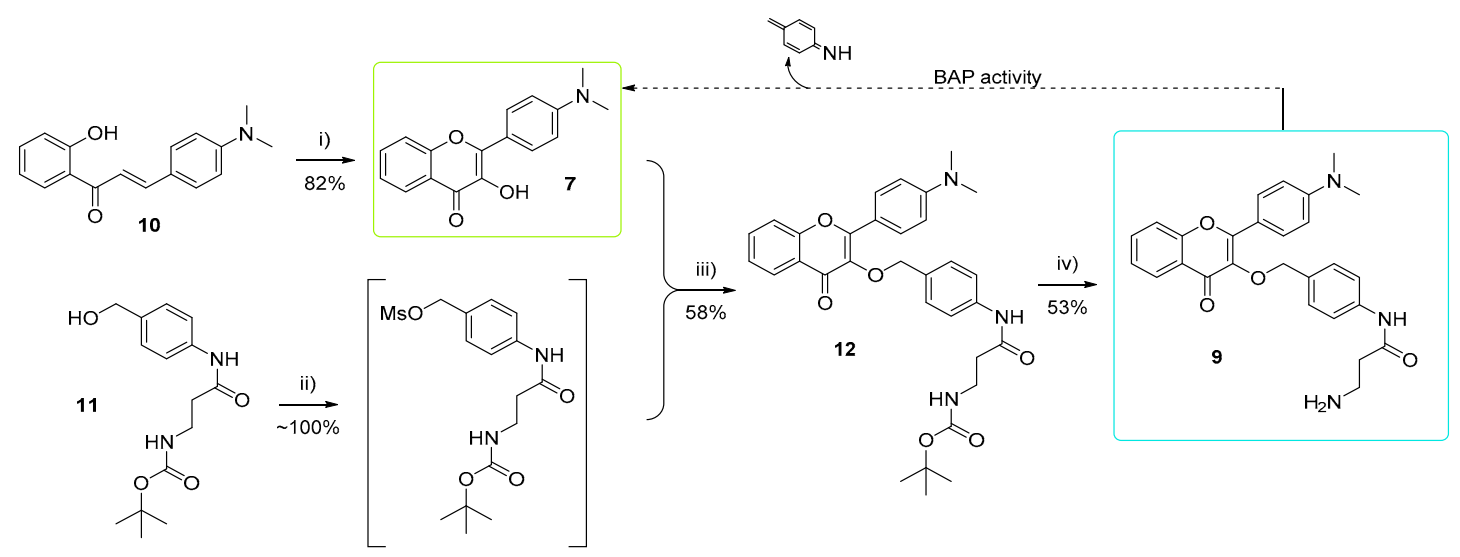

Scheme 3. Synthetic route for the preparation of fluorophore 7 and substrate 9 . Reagent and conditions used: (i) $\mathrm{EtOH} / \mathrm{THF} 1 / 1$ v:3, aq. $\mathrm{NaOH}, 0{ }^{\circ} \mathrm{C}, 35 \%$ aq. $\mathrm{H}_{2} \mathrm{O}_{2}$, r.t. 2 days. (ii) anhydrous DCM, inert atmosphere, acetone/ice bath, DIPEA, methanesulfonyl chloride, $2 \mathrm{~h}, 0^{\circ} \mathrm{C}$; (iii) DCM, $\mathrm{K}_{2} \mathrm{CO}_{3}$, overnight; (iv) EtOAc/DMF 5/1 v:v, 3M aq. $\mathrm{HCl}(5 v)$, r.t., $3 \mathrm{~h}$, then $\mathrm{NaOH}$.

\section{Results and Discussion}

\subsection{Synthesis of Substrate 9}

The chalcone precursor 10 (which was obtained via the previously reported aldol reaction between 2 '-hydroxyacetophenone and 4- $N, N$-dimethylaminobenzaldehyde [24]) was cyclized using hydrogen peroxide in the presence of a base to form 4'-diethylamino-3HF 7 (Scheme 3) [24]. To obtain the linker-amino acid moiety 11, $\beta$-alanine and the self-immolative linker precursor, 4 -aminobenzylalcohol, were coupled as reported previously [15]. The mesylate of $\mathbf{1 1}$ was formed in situ and coupled with the fluorophore $\mathbf{7}$, in the presence of potassium carbonate [15], to obtain the protected form of substrate $\mathbf{1 2}$. The ether conjugation in 12, which is acid labile due to the presence of the carbonyl group in the ortho position [25], necessitated a less acidic, two phase (ethyl acetate-water) removal of the Boc protecting group in order to obtain substrate 9 as a free amine.

\subsection{In Vitro Fluorescence Study}

The fluorescence excitation and emission spectra of fluorophore 7 and substrate 9 were recorded in a THF-water 1:1 mixture in order to solubilize the substrate while still resembling the polar protic environment of the bacterial growth media (Figure 2a, Table 1). Differences were observed in both the excitation and the emission spectra of the substrate $\mathbf{9}$ and the fluorophore $\mathbf{7}$.

Table 1. Excitation and emission maxima and Stokes shifts for BAP substrate 9 and fluorophore 7.

\begin{tabular}{cccc}
\hline & $\lambda_{\text {ex }}(\mathbf{n m})$ & $\lambda_{\text {em }}(\mathbf{n m})$ & Stokes Shift \\
\hline $\mathbf{7}$ & 426 & 536 & 110 \\
9 & $388(413)$ & 517 & 129 \\
\hline
\end{tabular}




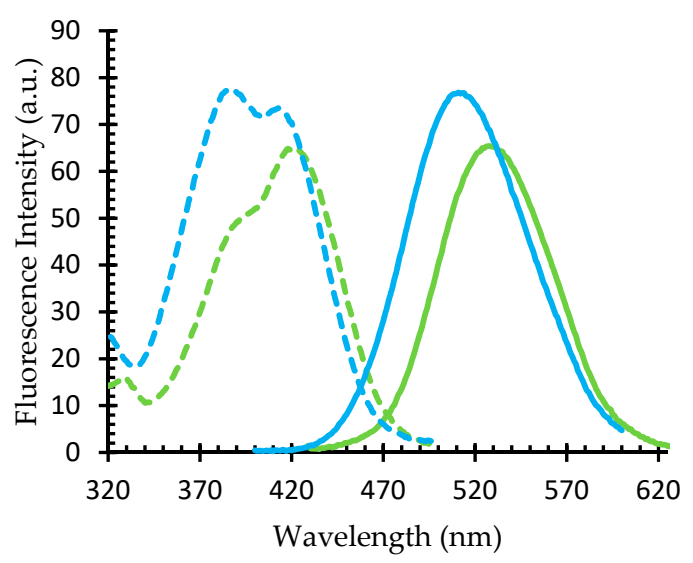

(a)

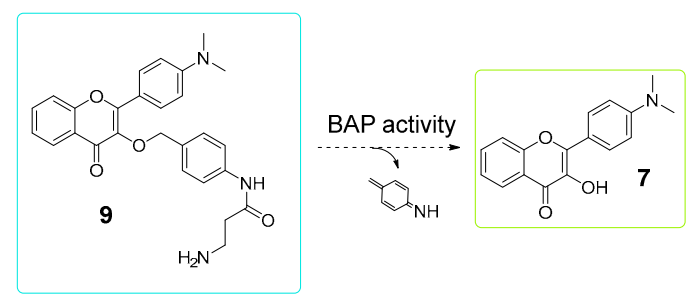

7

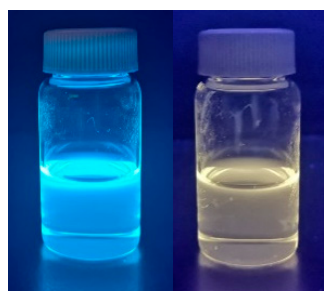

(b)

Figure 2. Fluorescence properties of BAP substrate 9 and fluorophore 7. (a) Fluorescence excitation (dashed line) and emission (solid line) of the substrate 9 (blue) and the enzymatic hydrolysis product, fluorophore 7 (green). (b) THF:water (1:1) solutions of 7 and 9.

Fluorophore 7 displayed yellow-green emission, with a maximum at $536 \mathrm{~nm}$ upon excitation at $426 \mathrm{~nm}$. A single fluorescence maximum —and the lack of the $\mathrm{N}^{*}$ and $\mathrm{T}^{*}$ dual emission-was observed, as expected, due to the perturbing of ESIPT by the H-bonded fluorophore in the protic solvent mixture [22]. This hindrance may also be the reason for a weaker excitation peak that is observed as a shoulder, with a maximum at $388 \mathrm{~nm}$.

For the substrate 9, ESIPT is inhibited (by design) via the substitution of the phenolic $\mathrm{OH}$, disrupting the opportunity for the formation of the tautomer form, hence a more prominent normal excitation at $388 \mathrm{~nm}$ (with a secondary peak at $413 \mathrm{~nm}$ ) and blue-shifted emission maximum at $517 \mathrm{~nm}$ was observed. The Stokes shifts of 129 and $110 \mathrm{~nm}$ for substrate 9 and fluorophore 7 (Table 1), respectively, are suitable for biosensing applications.

Despite the significantly overlapping emission peaks of $\mathbf{7}$ and $\mathbf{9}$, the visually observed fluorescence (on examination with a $365 \mathrm{~nm}$ light source) of the respective solutions reveals a distinct difference in the emission colour (Figure 2b).

\subsection{Biological Activity}

The substrate 9 was dissolved in agar for the in-house formulation of growth media. Petri dishes were then poured and either spot inoculated with a selection of 20 clinically relevant pathogens (10 Gram-negative, 8 Gram-positive, 2 yeasts) (Figure 3a-d) or streaked with selected strains (A. baumanii, E. cloacae as negative controls, P. aeruginosa and B. cepacia as BAP producers) (Figure 3e-h). After $24 \mathrm{~h}$ of incubation, the plates were visually inspected under visible (Figure $3 b, c)$ and UV light (365 nm) (Figure $3 \mathrm{~d}-\mathrm{h}$ ) to determine inhibitory profiles and the fluorescence emitted by the colonies. 
Table 2. Selected species for multispot inoculation. The spot numbers correlate to the numbered plate in Figure $3 a$.

\begin{tabular}{|c|c|c|c|}
\hline Spot \# & Organism & Spot \# & Organism \\
\hline 1 & E. coli NCTC 10418 * & 11 & S. pyogenes NCTC $8306^{*}$ \\
\hline 2 & K. pneumoniae NCTC 9528 * & 12 & S. aureus (MRSA) NCTC 11939 * \\
\hline 3 & P. rettgeri NCTC7475 & 13 & S. aureus NCTC $6571 *$ \\
\hline 4 & E. cloacae NCTC11936 & 14 & S. epidermidis NCTC $11047^{*}$ \\
\hline 5 & S. marcescens NCTC 10211 & 15 & L. monocytogenes NCTC 11994 \\
\hline 6 & S. typhimurium NCTC 74 & 16 & E. faecium NCTC 7171 \\
\hline 7 & P. aeruginosa NCTC 10662 & 17 & E. faecalis NCTC 775 \\
\hline 8 & Y. enterocolitica NCTC 11176 & 18 & B. subtilis NCTC $9372 *$ \\
\hline 9 & B. серасiа ATCC 25416 & 19 & C. albicans ATCC 90028 \\
\hline 10 & A. baumannii ATCC $19606^{* *}$ & 20 & C. glabrata NCPF 3943 * \\
\hline
\end{tabular}

* inhibited species; ${ }^{* *}$ partially inhibited with only 6 colonies formed.

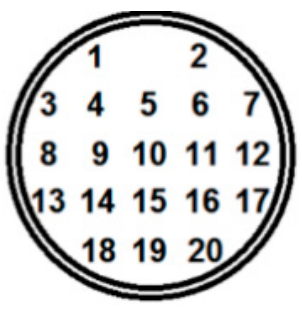

(a)

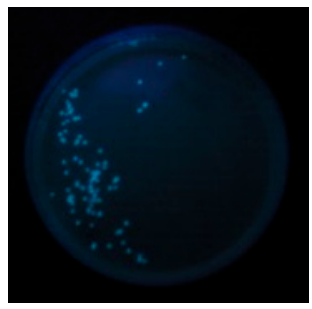

(e)

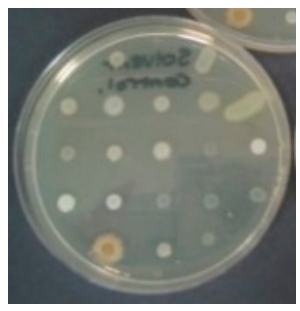

(b)

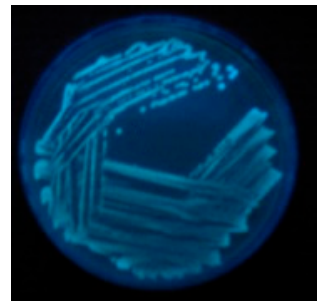

(f)

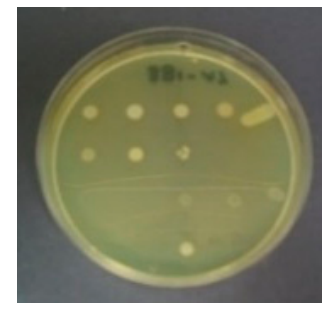

(c)

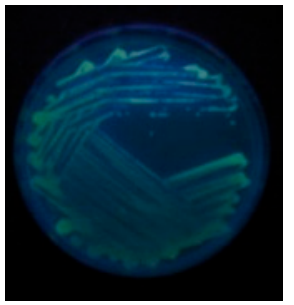

$(\mathrm{g})$

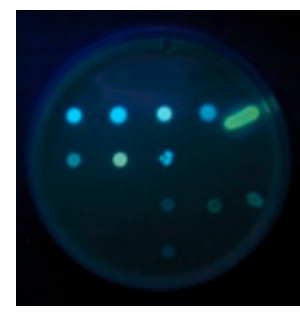

(d)

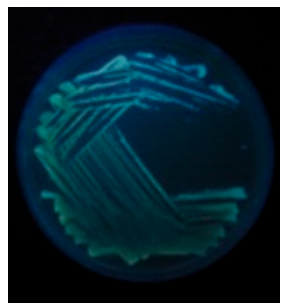

(h)

Figure 3. Spotted (top row) and streaked (bottom) inoculation of isolated colonies: (a) numbered strains corresponding to Table 2, (b) control plate containing no substrate; and plates supplemented with substrate 9 at $100 \mathrm{mg} / \mathrm{L}$ (c) colonies under natural light, (d) under $365 \mathrm{~nm}$ UV light source; agar containing $50 \mathrm{mg} / \mathrm{mL}$ of substrate 9, inoculated with isolates of (e) A. baumanii, (f) E. cloacae, (g) P. aeruginosa, and (h) B. cepacia.

\subsubsection{Antimicrobial Effect}

Flavonoids are known to express growth inhibitory bactericidal effects and have been suggested to result in membrane disruption and to interact with a broad range of enzymes [26]. In this study, the presence of substrate 9 in the medium had an inhibitory effect on the growth of 2 Gram-negative ( $E$ coli and K. pneumoniae), most Gram-positive (fully inhibited: S. pyogenes, Methicillin Resistant S. aureus (MRSA), S. aureus, S. epidermidis, B. subtilis; malformed colonies: L. monocytogenes, E. faecium, E. faecalis), and the two tested yeast species (C. albicans, C. glabrata), while A. baumanii developed malformed colonies. The reasons for this inhibitory profile have not been investigated, and further investigation is not within the scope of this study. 


\subsubsection{Fluorescence on Agar}

The aqueous agar-based growth medium supplemented with the substrate $9(100 \mathrm{mg} / \mathrm{mL})$ showed no background fluorescence upon excitation at $365 \mathrm{~nm}$ when observed by the naked eye. This is an ideal scenario, producing minimal interference with the detection signal, resulting in increased sensitivity, and reduced detection time.

Viable bacterial colonies, upon uptake and accumulation of the substrate $\mathbf{9}$, displayed blue emission. This correlates with a previously reported observation in which related derivatives-monopeptides labelled with $4^{\prime}$-dimethylamino-3HF 7-showed a significant increase in their fluorescence intensity upon their interaction with cell membrane [21].

Colony formation by all three BAP-producing bacteria, S. marcescens, B. cepacia, and P. aeruginosa, was uninterrupted, and localised yellow-green fluorescence was observed within the colonies, indicating the BAP-specific hydrolysis of the substrate 9 and good cellular adherence of the released fluorophore 7. The observed red-shifted (blue to yellow/green) emission confirms the regeneration of the phenolic $\mathrm{OH}$ of the fluorophore and the prevalence of its hydrated $\left(\mathrm{H}-\mathrm{N}^{*}\right)$ form in the protic polar cellular environment. The fluorescence intensity differences observed between the tested BAP-producing bacteria are consistent with the previously reported differences in BAP expression, with $S$. marcescens displaying lower levels of BAP activity than P. aeruginosa [12].

The images obtained under observation at $365 \mathrm{~nm}$ were processed with ImageJ by analysing the Red Green Blue (RGB) histograms for each colony on the multispot inoculation plates (using the same size as the area of interest) (Table S1, Figures S1-S7 and for the streaked colonies of E. cloacae and $P$. aeruginosa, respectively, and a mixed culture of these pathogens (measuring the whole plate area) to assess whether mixed cultures could be indicated using the substrate 9 (Figure S8a-c). The mean overall intensity (Figure 4a), green (Figure S7a), and blue (Figure S7b) values of the respective spot-inoculated colonies of the 20 pathogens allowed for differentiation between viable and inhibited species, which is a powerful tool for inclusion in susceptibility evaluations. Moreover, the mean red values (Figure 4b) clearly indicated the strains expressing BAP activity (spot \#5, 7, 9).

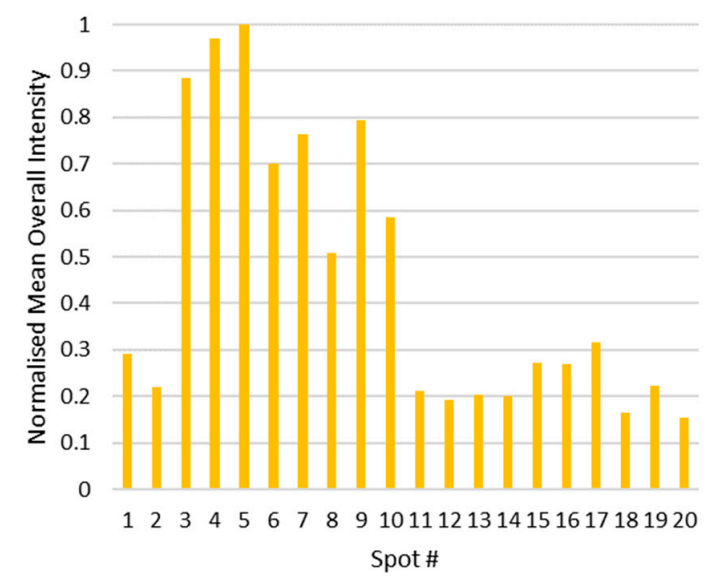

(a)

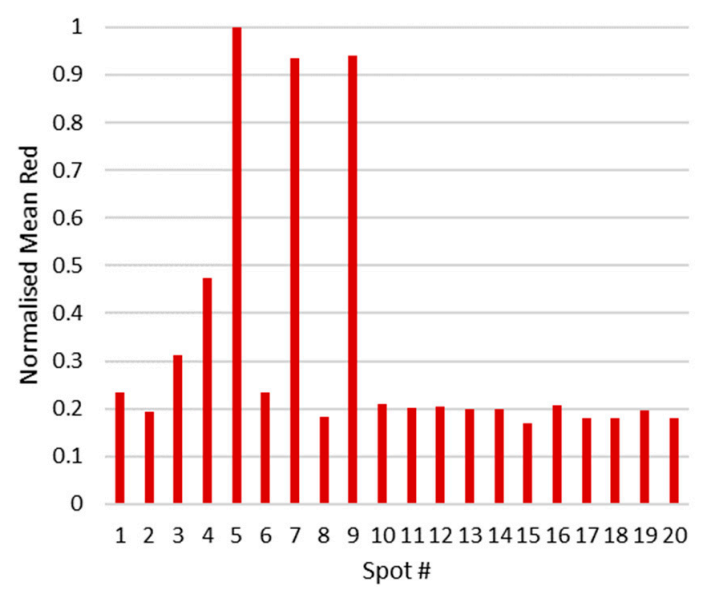

(b)

Figure 4. Comparison of the values generated using the RGB histograms (ImageJ) of the multispot inoculation plates (spot numbers correlating to microorganisms listed in Table 2) excited under a $365 \mathrm{~nm}$ excitation wavelength: (a) normalised mean overall intensity values for each of the 20 bacterial colonies; (b) normalized mean red intensity.

The intensity and respective R, G, B values generated on the whole-plate images of the streaked colonies (Figure S8) were conclusive when R/B and R/Int were calculated for mixed E. cloacae and 
P. aeruginosa culture (Figure S8c); these values fell between the values for the respective pure streaked cultures (Figure S8a,b).

\section{Materials and Methods}

All solvents and reagents were purchased from Sigma-Aldrich, Castle Hill, Sydney, Australia and Alfa-Aesar (Thermo Fisher Scientific Australia Pty. Ltd.), Scoresby, Victoria, Australia and used without any further purification or treatment. Thin layer chromatography was performed on Merck 60F-254 silica gel plates. Flash chromatography was performed on GRACE Reveleris X2 (In Vitro Technologies Pty. Ltd., Noble Park, Victoria, Australia). ${ }^{1} \mathrm{H}$ and ${ }^{13} \mathrm{C}-\mathrm{NMR}$ spectra were acquired on a Varian 400MR (Varian Australia Pty. Ltd., Mulgrave, Victoria, Australia) at $400 \mathrm{MHz}$ and $100 \mathrm{MHz}$, respectively. Coupling constants $(\mathrm{J})$ are in Hertz $(\mathrm{Hz})$, chemical shifts $(\delta)$ are expressed in parts per million $(\mathrm{ppm})$ and reported relative to tetramethylsilane (TMS) or relative to residual solvent peaks. Low resolution mass spectra were obtained on a Thermo Scientific TSQ Quantum Access Max LCMS/MS\&TLX1 Turboflow Chromatography System (Thermo Fisher Scientific Australia Pty. Ltd.), Scoresby, Victoria, Australia) in positive ion mode.

\subsection{Synthetic Procedures}

\subsubsection{Preparation of 4-Dimethylamino-2'-hydroxychalcone $\mathbf{1 0}$}

To a solution of 2'-hydroxy acetophenone $(2.65 \mathrm{~mL}, 22 \mathrm{mmol})$ and 4 - $N$-dimethylaminobenzaldehyde $(3.1 \mathrm{~g}, 21 \mathrm{mmol})$ in ethanol, an aqueous solution $(20 \mathrm{~mL})$ of $\mathrm{KOH}(3.7 \mathrm{~g}, 74 \mathrm{mmol})$ was added dropwise. The resulting solution was kept at $50{ }^{\circ} \mathrm{C}$ overnight. Upon completion, the reaction mixture was poured over water and concentrated $\mathrm{HCl}$ was added to reach $\mathrm{pH}$ 2. The precipitate formed was filtered and recrystallised from ethanol to give $\mathbf{1 0}$ as a red solid (2.83 g, $11 \mathrm{mmol}, 50 \%) .{ }^{1} \mathrm{H}-\mathrm{NMR}\left(400 \mathrm{MHz}, \mathrm{DMSO}-d_{6}\right) \delta 3.03\left(6 \mathrm{H}, \mathrm{s}, 2 \times \mathrm{CH}_{3}\right), 6.76(2 \mathrm{H}, \mathrm{d}$, $\left.J=8.0 \mathrm{~Hz}, 2 \times \mathrm{CH}_{\mathrm{Ph}}\right), 6.95-6.99\left(2 \mathrm{H}, \mathrm{m}, 2 \times \mathrm{CH}_{\mathrm{Ar}}\right), 7.53\left(1 \mathrm{H}, \mathrm{td}, J=1.6\right.$ and $\left.8.0 \mathrm{~Hz}, \mathrm{CH}_{\mathrm{Ar}}\right), 7.73-7.78$ $\left(3 \mathrm{H}, \mathrm{m}, 2 \times \mathrm{CH}_{\mathrm{Ph}}\right.$ and $\left.=\mathrm{CH}\right), 7.83(1 \mathrm{H}, \mathrm{d}, J=15.2 \mathrm{~Hz},=\mathrm{CH}), 8.26\left(1 \mathrm{H}, \mathrm{dd}, J=1.6\right.$ and $\left.8.0 \mathrm{~Hz}, \mathrm{CH}_{\mathrm{Ar}}\right)$; ${ }^{13} \mathrm{C}-\mathrm{NMR}\left(100 \mathrm{MHz}\right.$, DMSO- $\left.d_{6}\right) \delta 40.6\left(2 \times \mathrm{CH}_{3}\right), 112.2\left(2 \times \mathrm{CH}_{\mathrm{Ph}}\right), 115.1\left(=\mathrm{CH}_{\alpha}\right), 118.2(\mathrm{CH}), 119.3$ (CH), 120.9 (quat., $\mathrm{C}-2), 122.1$ (quat., $\mathrm{C}-1^{\prime}$ or $\left.6^{\prime}\right), 130.9(\mathrm{CH}-3$ or 6$), 131.9\left(2 \times \mathrm{CH}_{\mathrm{Ph}}\right), 136.2(\mathrm{CH}-4$ or 5$)$, $147.0\left(=\mathrm{CH}_{\beta}\right), 152.8$ (quat., C-4' $), 162.8$ (quat., $\left.\mathrm{C}-1\right), 193.6$ (quat., $\mathrm{C}=\mathrm{O}$ ); MS (ESI) $m / z 268.05[\mathrm{MH}]^{+}$; HRMS $m / z$ Found: 290.11565, calcd for $\mathrm{C}_{17} \mathrm{H}_{17} \mathrm{NO}_{2} \mathrm{Na} 290.11515$.

\subsubsection{Preparation of 7}

To a solution of 4-dimethylamino-2'-hydroxychalcone $10(2.5 \mathrm{~g}, 9.26 \mathrm{mmol})$ in an ethanol/THF mixture (1/1 v:v) $(70 / 70 \mathrm{~mL})$, an aqueous solution $(12 \mathrm{~mL})$ of $\mathrm{NaOH}(1.82 \mathrm{~g}, 45.5 \mathrm{mmol})$ was added. The resulting reaction mixture was cooled to $0{ }^{\circ} \mathrm{C}$, and $35 \%$ aqueous $\mathrm{H}_{2} \mathrm{O}_{2}(9 \mathrm{~mL})$ was added dropwise. The resulting solution was stirred at room temperature for 2 days and then poured over water $(150 \mathrm{~mL})$. Adjustment of the $\mathrm{pH}$ to $3-4$ with $1 \mathrm{~N} \mathrm{HCl}$ resulted in a yellow precipitate upon standing overnight, this crude solid was filtered and recrystallised from ethanol to give 7 as an orange crystalline solid $(2.13 \mathrm{~g}, 7.6 \mathrm{mmol}, 82 \%) .{ }^{1} \mathrm{H}-\mathrm{NMR}\left(400 \mathrm{MHz}, \mathrm{DMSO}-d_{6}\right) \delta 3.02\left(6 \mathrm{H}, \mathrm{s}, 2 \times \mathrm{CH}_{3}\right), 6.84(2 \mathrm{H}, \mathrm{d}, J=9.2 \mathrm{~Hz}$, $\left.2 \times \mathrm{CH}_{\mathrm{Ph}}\right), 7.44(1 \mathrm{H}, \mathrm{t}, J=7.2 \mathrm{~Hz}, \mathrm{CH}), 7.727-7.77(2 \mathrm{H}, \mathrm{m}, 2 \times \mathrm{CH}), 8.08(1 \mathrm{H}, \mathrm{dd}, J=0.4$ and $8.0 \mathrm{~Hz}$, $\mathrm{CH}), 8.12\left(2 \mathrm{H}, \mathrm{d}, J=9.2 \mathrm{~Hz}, 2 \times \mathrm{CH}_{\mathrm{Ph}}\right), 9.19(1 \mathrm{H}, \mathrm{br} \mathrm{s}, \mathrm{OH}) ;{ }^{13} \mathrm{C}-\mathrm{NMR}\left(100 \mathrm{MHz}, \mathrm{DMSO}-d_{6}\right) \delta 40.6$ $\left(\mathrm{CH}_{3}, 2 \times \mathrm{CH}_{3}\right), 111.8\left(\mathrm{CH}-3^{\prime}\right.$ and $\left.5^{\prime}\right), 118.4(\mathrm{CH}), 118.6$ (quat.), 121.9 (quat.), 124.7 (CH-6 or 7), 125.05 (CH-5 or 8), $129.4\left(\mathrm{CH}-2^{\prime}\right.$ and 6'), $133.5(\mathrm{CH}), 137.7$ (quat.), 147.25 (quat., $\left.\mathrm{C}-1^{\prime}\right), 151.5$ (quat., $\left.\mathrm{C}-4^{\prime}\right), 154.7$ (quat., C-4a or 8a), 172.4 (quat., C-4); MS (ESI) $\mathrm{m} / \mathrm{z} 282.03$ [MH] ${ }^{+}$; HRMS $\mathrm{m} / \mathrm{z}$ found 304.09485 calcd for $\mathrm{C}_{17} \mathrm{H}_{15} \mathrm{NO}_{3} \mathrm{Na} 304.09441$. 
3.1.3. Preparation of 2-( $p$-Dimethylaminophenyl)-3-[4-\{3'-(tert-butoxycarbonylamino) Propanamido Benzyloxy]-flavone 12

$N$-(N'-(tert-Butoxycarbonyl)- $\beta$-alanyl)-4-aminobenzyl alcohol 11 (0.58 g, $1.98 \mathrm{mmol})$ was dissolved in anhydrous DCM (20 mL) under inert atmosphere and kept in an acetone/ice bath. Then, $\mathrm{N}, \mathrm{N}$-diisopropylethylamine (DIPEA) $(0.31 \mathrm{~g}, 2.37 \mathrm{mmol})$ was added followed by the dropwise addition of methanesulfonyl chloride $(0.27 \mathrm{~g}, 2.37 \mathrm{mmol})$. The reaction mixture was stirred for $2 \mathrm{~h}$ at $0-5{ }^{\circ} \mathrm{C}$. The reaction mixture was poured over an ice/conc. $\mathrm{HCl}$ mixture $(35 / 15 \mathrm{~mL})$, then the separated DCM layer was used without further purification in the next step assuming $100 \%$ yield of the mesylated product (based on TLC). In a separate flask, 2-4'-(dimethylamino)phenyl-3-hydroxyflavone 7 (0.4 g, $1.42 \mathrm{mmol})$ was dissolved in DCM $(50 \mathrm{~mL})$, and potassium carbonate $(1.17 \mathrm{~g}, 7.1 \mathrm{mmol})$ was added and stirred at room temperature for $1 \mathrm{~h}$. The solution of the mesylate formed previously was added dropwise, and the mixture was left to stir overnight. The organic residue was then extracted with water $(100 \mathrm{~mL}), 1 \mathrm{M} \mathrm{HCl}(50 \mathrm{~mL})$, followed by saturated brine $(50 \mathrm{~mL})$, then dried over $\mathrm{Na}_{2} \mathrm{SO}_{4}$ and concentrated under vacuum. The resulting yellow solid was recrystallised from an ethyl acetate-hexane mixture to give the crude product. Column chromatography using a gradient of $15 \%$ to $60 \%$ petroleum ether in ethyl acetate was carried out to obtain 12 as a yellow solid $(0.475 \mathrm{~g}, 0.82 \mathrm{mmol}, 58 \%) ;{ }^{1} \mathrm{H}-\mathrm{NMR}$ $\left(400 \mathrm{MHz}, \mathrm{DMSO}-d_{6}\right) \delta 1.37\left(9 \mathrm{H}, \mathrm{s}, \mathrm{C}\left(\mathrm{CH}_{3}\right)_{3}\right), 2.46\left(2 \mathrm{H}, \mathrm{t}, J=7.2 \mathrm{~Hz}, \mathrm{CH}_{2 \beta}\right), 3.03\left(6 \mathrm{H}, \mathrm{s}, 2 \times \mathrm{CH}_{3}\right), 3.21$ $\left(2 \mathrm{H}, \mathrm{q}, J=6.8 \mathrm{~Hz}, \mathrm{CH}_{2 \alpha}\right), 5.01\left(2 \mathrm{H}, \mathrm{s}, \mathrm{CH}_{2} \mathrm{O}\right), 6.81(2 \mathrm{H}, \mathrm{d}, J=9.2 \mathrm{~Hz}, 2 \times \mathrm{CH}), 6.85\left(1 \mathrm{H}, \mathrm{m}, \mathrm{NH}_{\text {carbamate }}\right)$, $7.32(2 \mathrm{H}, \mathrm{d}, J=8.4 \mathrm{~Hz}, 2 \times \mathrm{CH}), 7.47(1 \mathrm{H}, \mathrm{t}, J=7.47 \mathrm{~Hz}, \mathrm{CH}-6$ or 7$), 7.54(2 \mathrm{H}, \mathrm{d}, J=8.4 \mathrm{~Hz}, 2 \times \mathrm{CH}), 7.71$ $(1 \mathrm{H}, \mathrm{d}, J=8.4 \mathrm{~Hz}, \mathrm{CH}-8$ or 5$), 7.78(1 \mathrm{H}, \mathrm{t}, J=7.72 \mathrm{~Hz}, \mathrm{CH}-6$ or 7$), 8.02(2 \mathrm{H}, \mathrm{d}, J=9.2 \mathrm{~Hz}, 2 \times \mathrm{CH}), 8.09$ $(1 \mathrm{H}, \mathrm{dd}, J=4.0 \mathrm{~Hz}$ and $8.0 \mathrm{~Hz}, \mathrm{CH}-8$ or 5$), 9.89\left(1 \mathrm{H}, \mathrm{s}, \mathrm{NH}_{\text {amide }}\right) ;{ }^{13} \mathrm{C}-\mathrm{NMR}\left(100 \mathrm{MHz}, \mathrm{DMSO}-d_{6}\right) \delta 28.2$ $\left(3 \times \mathrm{CH}_{3}\right), 36.5\left(\mathrm{CH}_{2 \beta}\right), 36.75\left(\mathrm{CH}_{2 \alpha}\right), 39.6\left(2 \times \mathrm{CH}_{3}\right), 72.40\left(\mathrm{OCH}_{2}\right), 77.6$ (quat., $\left.\mathrm{C}\left(\mathrm{CH}_{3}\right)_{3}\right), 111.2\left(\mathrm{CH}-3^{\prime}\right.$ and $\left.5^{\prime}\right), 116.70$ (quat., $\left.\mathrm{C}-1^{\prime}\right), 118.14(\mathrm{CH}-8), 118.70\left(\mathrm{CH}-3^{\prime \prime}\right.$ and $\left.5^{\prime \prime}\right), 123.5$ (quat., C-4a), 124.75 (CH-5 or 6), 124.81 (CH-5 or 6), 129.0 (CH-2" and 6"), 129.7 (CH-2' and 6'), 131.4 (quat., C-1"), 133.53 (CH-7), 137.7 (quat., C-3), 139.0 (quat., C-4"), 151.7 (quat., $C-4^{\prime}$ ), 154.4 (quat., $C-8 a$ ), 155.5 (quat., $C=\mathrm{O}_{\text {carbamate), }}$

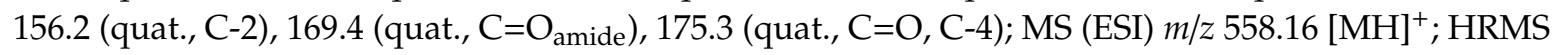
Found 580.24213 calcd for $\mathrm{C}_{32} \mathrm{H}_{35} \mathrm{~N}_{3} \mathrm{O}_{6} \mathrm{Na} 580.24181$.

\subsubsection{Preparation of 2-(p-Dimethylaminophenyl)-3-[4-propanamido benzyloxy]-flavone 9}

2-(p-dimethylaminophenyl)-3-[4-\{3'-(tert-butoxycarbonylamino)propanamidobenzyloxy]-flavone 12 (250 mg, $0.45 \mathrm{mmol})$ was dissolved in an ethyl acetate $(10 \mathrm{~mL})$ and DMF $(2 \mathrm{~mL})$ mixture, then $3 \mathrm{M}$ aqueous $\mathrm{HCl}(10 \mathrm{~mL})$ was added. The resulting reaction mixture was stirred at room temperature for $3 \mathrm{~h}$. To the separated aqueous layer, ethyl acetate was added, and the $\mathrm{pH}$ of this stirred mixture was adjusted to 7 using $5 \mathrm{M}$ aqueous $\mathrm{NaOH}$. The precipitate formed was filtered and recrystallized from ethyl acetate to give 9 as a yellow solid $(108 \mathrm{mg}, 0.24 \mathrm{mmol}, 53 \%)$. ${ }^{1} \mathrm{H}-\mathrm{NMR}\left(400 \mathrm{MHz}, \mathrm{DMSO}-d_{6}\right) \delta$ $2.42\left(2 \mathrm{H}, \mathrm{t}, J=6.4 \mathrm{~Hz}, \mathrm{CH}_{2 \alpha}\right), 2.86\left(2 \mathrm{H}, \mathrm{m}, \mathrm{CH}_{2 \alpha}\right), 3.03\left(6 \mathrm{H}, \mathrm{s}, 2 \times \mathrm{CH}_{3}\right), 5.01\left(2 \mathrm{H}, \mathrm{s}, \mathrm{CH}_{2} \mathrm{O}\right), 6.82(2 \mathrm{H}, \mathrm{d}$, $J=9.3 \mathrm{~Hz}, 2 \times \mathrm{CH}), 7.33(2 \mathrm{H}, \mathrm{d}, J=8.4 \mathrm{~Hz}, 2 \times \mathrm{CH}), 7.47(1 \mathrm{H}, \mathrm{t}, J=7.5 \mathrm{~Hz}, \mathrm{CH}-6$ or 7$), 7.55(2 \mathrm{H}, \mathrm{d}$, $J=8.4 \mathrm{~Hz}, 2 \times \mathrm{CH}), 7.72(1 \mathrm{H}, \mathrm{d}, J=7.8 \mathrm{~Hz}, \mathrm{CH}-8$ or 5$), 7.79(1 \mathrm{H}, \mathrm{t}, J=7.8 \mathrm{~Hz}, \mathrm{CH}-6$ or 7$), 8.03(2 \mathrm{H}, \mathrm{d}$, $J=9.2 \mathrm{~Hz}, 2 \times \mathrm{CH}), 8.09(1 \mathrm{H}, \mathrm{dd}, J=4.0$ and $8.0 \mathrm{~Hz}, \mathrm{CH}-8$ or 5$), 10.11\left(1 \mathrm{H}, \mathrm{s}, \mathrm{NH}_{\text {amide }}\right) ;{ }^{13} \mathrm{C}-\mathrm{NMR}$ $\left(100 \mathrm{MHz}, \mathrm{DMSO}-d_{6}\right) \delta 35.1\left(\mathrm{CH}_{2 \beta}\right), 35.8\left(\mathrm{CH}_{2 \alpha}\right), 39.6\left(2 \times \mathrm{CH}_{3}\right), 72.40\left(\mathrm{OCH}_{2}\right), 111.2\left(\mathrm{CH}-3^{\prime}\right.$ and $\left.5^{\prime}\right)$, 116.7 (quat., C-1'), 118.1 (CH-8), 118.8 (CH-3" and 5"), 123.5 (quat., C-4a), 124.7 (CH-5 or 6), 124.8 (CH-5 or 6), 129.0 (CH-2" and 6"), 129.7 (CH-2' and 6'), 131.65 (quat., C-1"), 133.5 (CH-7), 137.7 (quat., C-3), 138.7 (quat., C-4"), 151.7 (quat., C-4' ), 154.4 (quat., C-8a), 156.2 (quat., C-2), 168.5 (quat., NHC=O), 173.3 (quat., $\mathrm{C}=\mathrm{O}, \mathrm{C}-4$ ); MS (ESI) $\mathrm{m} / z 458.05[\mathrm{MH}]^{+}$; HRMS found 480.18987 calcd for $\mathrm{C}_{27} \mathrm{H}_{27} \mathrm{~N}_{3} \mathrm{O}_{4} \mathrm{Na}$ 480.18938.

\subsection{In Vitro Fluorescence Studies}

The fluorescence of $0.01 \mathrm{mg} / \mathrm{mL}$ aqueous THF (1:1 v:v) solutions of the substrate and the fluorophore was evaluated with $5 \mathrm{~nm}$ slit width at low sensitivity, with $1 \mathrm{~nm}$ steps for emission and excitation, respectively. 


\subsection{Biological Evaluation}

\subsubsection{Preparation of Culture Media Containing Substrate 9}

Columbia agar was prepared as follows: $41 \mathrm{~g}$ of Columbia agar (Oxoid Basingstoke, UK) was added to deionized water, and the volume was made up to $1 \mathrm{~L}$. The medium was sterilized by autoclaving at $116{ }^{\circ} \mathrm{C}$ for $20 \mathrm{~min}$ and left to cool at $50{ }^{\circ} \mathrm{C} .2 \mathrm{mg}$ of the substrate to be tested was initially dissolved in $100 \mu \mathrm{L}$ of $N$-methylpyrrolidone, and this was added to Columbia agar (made up to $20 \mathrm{~mL}$ ) then poured into sterile Petri dishes to give a final concentration of $100 \mathrm{mg} / \mathrm{L}$ for the substrate 9. Columbia agar incorporating an equivalent concentration of $\mathrm{N}$-methylpyrrolidone was used as a growth control.

\subsubsection{Microbial Suspension Preparation}

Microbial reference strains were obtained from either the National Collection of Type Cultures (NCTC) or the National Collection of Pathogenic Fungi (NCPF), which are both located at the Central Public Health England Laboratory, Colindale, UK or the American Type Culture Collection (ATCC), Manassas, USA. The 20 test microorganisms were maintained on Columbia agar.

\subsubsection{Multipoint Inoculation}

Colonies of each microbial strain were harvested using a loop from overnight cultures on Columbia agar. These were suspended in sterile deionized water to a suspension equivalent to $0.5 \mathrm{McF}$ arland units using a densitometer. $100 \mu \mathrm{L}$ of this suspension was pipetted into the corresponding wells of a multipoint inoculation device. Each set of plates received $1 \mu \mathrm{L}$ of bacterial suspension, giving $1.5 \times 10^{5}$ organisms per spot on each inoculation. Twenty strains were inoculated per plate, and the plates were incubated for $18 \mathrm{~h}$ in air at $37^{\circ} \mathrm{C}$.

\subsubsection{Activity Determination}

After incubation, the activity of the microorganisms with the test substrates was determined by observing the plates under UV irradiation at $365 \mathrm{~nm}$ and comparing with the substrate-free control.

\section{Conclusions}

In this work, a novel 3-hydroxyflavone-based $\beta$-alanine aminopeptidase substrate was designed, synthesised, characterised for its chemical and optical properties, and evaluated on an agar growth medium for its potential use as a selective fluorescent probe for the detection of BAP-producing bacteria. The fluorescence characteristics in aqueous solution were as expected. Conversion of the fluorophore 7 into substrate 9 resulted in the hindrance of ESIPT and a change in the emission wavelength. The agar-based growth medium supplemented with the substrate showed no background fluorescence, which is desirable for this application. Upon inoculation with the selected pathogens, growth inhibition was observed for some of the species; however, the microorganisms of interest formed viable, fully grown colonies. Viable colonies displayed blue fluorescence upon the accumulation of the substrate, confirming the cell-wall permeability of the substrate and this, as an added benefit, generally indicating viable bacteria. More significantly, BAP-producing bacteria displayed green fluorescence upon selective hydrolysis of the substrate. This fluorescence was localised within the colonies, which is beneficial for their identification. The change in fluorescence emission upon enzymatic cleavage was readily observed under a UV lamp, while a simple-to-conduct image analysis allowed the differentiation of BAP producers. The simultaneous detection and differentiation of viable colonies and BAP producers (while displaying no background fluorescence) achieved using substrate $\mathbf{9}$ is a desirable advancement to the previously reported fluorogenic BAP substrates.

Supplementary Materials: The following are available online, Table S1: RGB and intensity values obtained by ImageJ RGB histogram on corresponding colonies of the multispot inoculated plates; Figure S1: Histograms of 
(a) intensity, (b) RGB, (c) red, (d) green, (e) blue values for spot \#20 as an example for typical growth-inhibited species; Figure S2: Histograms of (a) intensity, (b) RGB, (c) red, (d) green, (e) blue values for spot \#16 as an example for semi-inhibited BAP-negative species; Figure S3: Histograms of (a) intensity, (b) RGB, (c) red, (d) green, (e) blue values for spot \#3 as an example for well-grown BAP-negative species; Figure S4: Histograms of (a) intensity, (b) RGB, (c) red, (d) green, (e) blue values for spot \#7 P. aeruginosa BAP-positive strain; Figure S5: Histograms of (a) intensity, (b) RGB, (c) red, (d) green, (e) blue values for spot \#5 S. marcescens BAP-positive strain; Figure S6: Histograms of (a) intensity, (b) RGB, (c) red, (d) green, (e) blue values for spot \#9 B. cepacia BAP-positive strain; Figure S7: Bar charts of ImageJ histogram values of the spot-inoculated colonies for each of the 20 strains of (a) green, and (b) blue component; Figure S8: Streaked colonies; intensity, and respective R, G, B values and their ratios based on Image image processing of the plates under a $365 \mathrm{~nm}$ light source, and RGB histograms of (a) E. cloacae (BAP-negative), (b) P. aeruginosa (BAP-positive), (c) mixed culture of E. cloacae and P. aeruginosa; Figure S9: ${ }^{1} \mathrm{H}-\mathrm{NMR}$ of 10 in DMSO- $d_{6}$; Figure S10 HRMS of 10; Figure S11: ${ }^{1} \mathrm{H}-\mathrm{NMR}$ of 7 in DMSO- $d_{6}$; Figure S12: HRMS of 7; Figure S13: ${ }^{1} \mathrm{H}-\mathrm{NMR}$ of 12 in DMSO-d6; Figure S14: HRMS of 12; Figure S15: ${ }^{1} \mathrm{H}$ NMR of 9 in DMSO-d6; Figure S16: HRMS of 9.

Author Contributions: Conceptualization, L.V., D.E.H., J.D.P., and P.W.G.; Data curation, E.Y.N.; Formal analysis, L.V., E.Y.N. and J.D.P.; Funding acquisition, D.E.H. and P.W.G.; Methodology, P.W.G.; Resources, J.D.P. and P.W.G.; Supervision, D.E.H.; Writing-original draft, L.V.; Writing—review \& editing, D.E.H., J.D.P., and P.W.G.

Funding: This research was funded by the National Health and Medical Research Council (Australia), grant number APP1043746.

Conflicts of Interest: The authors declare no conflict of interest.

\section{References}

1. Hays, J.P.; Mitsakakis, K.; Luz, S.; van Belkum, A.; Becker, K.; van den Bruel, A.; Harbarth, S.; Rex, J.H.; Simonsen, G.S.; Werner, G.; et al. The successful uptake and sustainability of rapid infectious disease and antimicrobial resistance point-of-care testing requires a complex 'mix-and-match' implementation package. Eur. J. Clin. Microbiol. Infect. Dis. 2019, 38, 1015-1022. [CrossRef] [PubMed]

2. Váradi, L.; Luo, J.L.; Hibbs, D.E.; Perry, J.D.; Anderson, R.J.; Orenga, S.; Groundwater, P.W. Methods for the detection and identification of pathogenic bacteria: Past, present, and future. Chem. Soc. Rev. 2017, 46, 4818-4832. [CrossRef] [PubMed]

3. Van Belkum, A.; Durand, G.; Peyret, M.; Chatellier, S.; Zambardi, G.; Schrenzel, J.; Shortridge, D.; Engelhardt, A.; Dunne, W.M., Jr. Rapid clinical bacteriology and its future impact. Ann. Lab. Med. 2013, 33, 14-27. [CrossRef] [PubMed]

4. Orenga, S.; James, A.L.; Manafi, M.; Perry, J.D.; Pincus, D.H. Enzymatic substrates in microbiology. J. Microbiol. Methods 2009, 79, 139-155. [CrossRef] [PubMed]

5. Perry, J.D.; James, A.L.; Morris, K.A.; Oliver, M.; Chilvers, K.F.; Reed, R.H.; Gould, F.K. Evaluation of novel fluorogenic substrates for the detection of glycosidases in Escherichia coli and enterococci. J. Appl. Microbiol. 2006, 101, 977-985. [CrossRef]

6. Perry, J.D.; Laine, L.; Hughes, S.; Nicholson, A.; Galloway, A.; Gould, F.K. Recovery of antimicrobial-resistant Pseudomonas aeruginosa from sputa of cystic fibrosis patients by culture on selective media. J. Antimicrob. Chemother. 2008, 61, 1057-1061. [CrossRef] [PubMed]

7. Carnell, S.C.; Perry, J.D.; Borthwick, L.; Vollmer, D.; Biboy, J.; Facchini, M.; Bragonzi, A.; Silipo, A.; Vergunst, A.C.; Vollmer, W.; et al. Targeting the bacterial cytoskeleton of the Burkholderia cepacia complex for antimicrobial development: A cautionary tale. Int. J. Mol. Sci. 2018, 19, 1604. [CrossRef] [PubMed]

8. Rossen, J.W.A.; Dombrecht, J.; Vanfleteren, D.; De Bruyne, K.; van Belkum, A.; Rosema, S.; Lokate, M.; Bathoorn, E.; Reuter, S.; Grundmann, H.; et al. Epidemiological typing of Serratia marcescens isolates by whole-genome multilocus sequence typing. J. Clin. Microbiol. 2019, 57, e01652-e01658. [CrossRef]

9. Zaytsev, A.V.; Anderson, R.J.; Bedernjak, A.; Groundwater, P.W.; Huang, Y.; Perry, J.D.; Orenga, S.; Roger-Dalbert, C.; James, A. Synthesis and testing of chromogenic phenoxazinone substrates for $\beta$-alanyl aminopeptidase. Org. Biomol. Chem. 2008, 6, 682-692. [CrossRef]

10. Váradi, L.; Gray, M.; Groundwater, P.W.; Hall, A.J.; James, A.L.; Orenga, S.; Perry, J.D.; Anderson, R.J. Synthesis and evaluation of fluorogenic 2-amino-1,8-naphthyridine derivatives for the detection of bacteria. Org. Biomol. Chem. 2012, 10, 2578-2589. [CrossRef] 
11. Cellier, M.; James, A.L.; Orenga, S.; Perry, J.D.; Rasul, A.K.; Stanforth, S.P. Detection of l-alanylaminopeptidase activity in microorganisms using chromogenic self-immolative enzyme substrates. Bioorg. Med. Chem. Lett. 2017, 27, 2102-2106. [CrossRef] [PubMed]

12. Váradi, L.; Hibbs, D.E.; Orenga, S.; Babolat, M.; Perry, J.D.; Groundwater, P.W. $\beta$-alanyl aminopeptidase-activated fluorogenic probes for the rapid identification of Pseudomonas aeruginosa in clinical samples. RSC Adv. 2016, 6, 58884-58889. [CrossRef]

13. Cellier, M.; Fazackerley, E.; James, A.L.; Orenga, S.; Perry, J.D.; Turnbull, G.; Stanforth, S.P. Synthesis of 2-arylbenzothiazole derivatives and their application in bacterial detection. Bioorg. Med. Chem. 2014, 22, 1250-1261. [CrossRef] [PubMed]

14. Mihalcescu, I.; Van-Melle Gateau, M.; Chelli, B.; Pinel, C.; Ravanat, J.L. Green autofluorescence, a double edged monitoring tool for bacterial growth and activity in micro-plates. Phys. Biol. 2015, 12, 066016. [CrossRef]

15. Váradi, L.; Wang, M.; Mamidi, R.R.; Luo, J.L.; Perry, J.D.; Hibbs, D.E.; Groundwater, P.W. A latent green fluorescent styrylcoumarin probe for the selective growth and detection of Gram negative bacteria. Bioorg. Med. Chem. 2018, 26, 4745-4750. [CrossRef] [PubMed]

16. Cellier, M.; James, A.L.; Orenga, S.; Perry, J.D.; Turnbull, G.; Stanforth, S.P. The synthesis of 1-alanyl and $\beta$-alanyl derivatives of 2-aminoacridone and their application in the detection of clinically-important microorganisms. PLoS ONE 2016, 11, e0158378. [CrossRef]

17. Perry, J.D.; Morris, K.A.; James, A.L.; Oliver, M.; Gould, F.K. Evaluation of novel chromogenic substrates for the detection of bacterial $\beta$-glucosidase. J. Appl. Microbiol. 2007, 102, 410-415. [CrossRef]

18. Sarkar, M.; Guha Ray, J.; Sengupta, P.K. Effect of reverse micelles on the intramolecular excited state proton transfer (ESPT) and dual luminescence behaviour of 3-hydroxyflavone. Spectrochim. Acta Part A 1996, 52, 275-278. [CrossRef]

19. Chou, P.T.; Martinez, M.L.; Clements, J.H. Reversal of excitation behavior of proton-transfer vs. charge-transfer by dielectric perturbation of electronic manifolds. J. Phys. Chem. 1993, 97, 2618-2622. [CrossRef]

20. Klymchenko, A.S.; Pivovarenko, V.G.; Ozturk, T.; Demchenko, A.P. Modulation of the solvent-dependent dual emission in 3-hydroxychromones by substituents. New J. Chem. 2003, 27, 1336-1343. [CrossRef]

21. Postupalenko, V.Y.; Shvadchak, V.V.; Duportail, G.; Pivovarenko, V.G.; Klymchenko, A.S.; Mély, Y. Monitoring membrane binding and insertion of peptides by two-color fluorescent label. Biochim. Biophys. Acta (BBA) 2011, 1808, 424-432. [CrossRef] [PubMed]

22. Shynkar, V.V.; Klymchenko, A.S.; Piémont, E.; Demchenko, A.P.; Mély, Y. Dynamics of intermolecular hydrogen bonds in the excited states of $4^{\prime}$-dialkylamino-3-hydroxyflavones. On the pathway to an ideal fluorescent hydrogen bonding sensor. J. Phys. Chem. A 2004, 108, 8151-8159. [CrossRef]

23. Liu, Y.; Feng, G. A visible light excitable colorimetric and fluorescent ESIPT probe for rapid and selective detection of hydrogen sulfide. Org. Biomol. Chem. 2014, 12, 438-445. [CrossRef]

24. Lin, C.C.; Chen, C.L.; Chung, M.W.; Chen, Y.J.; Chou, P.T. Effects of multibranching on 3-hydroxyflavone-based chromophores and the excited-state intramolecular proton transfer dynamics. J. Phys. Chem. A 2010, 114, 10412-10420. [CrossRef] [PubMed]

25. Fletcher, S.; Gunning, P.T. Mild, efficient and rapid o-debenzylation of ortho-substituted phenols with trifluoroacetic acid. Tetrahedron Lett. 2008, 49, 4817-4819. [CrossRef]

26. Montenegro, D.C.; Gonçalves, F.G.; Oliveira Filho, A.A.; Lira, B.A.; Cassiano, T.T.; Lima, T.N.; Barbosa-Filho, M.J.; Diniz, D.M.; Pessôa, L.H. In silico study and bioprospection of the antibacterial and antioxidant effects of flavone and its hydroxylated derivatives. Molecules 2017, 22, 869. [CrossRef] [PubMed]

(C) 2019 by the authors. Licensee MDPI, Basel, Switzerland. This article is an open access article distributed under the terms and conditions of the Creative Commons Attribution (CC BY) license (http://creativecommons.org/licenses/by/4.0/). 